\title{
The Competent School Principal: Personality Traits and Professional Skills
}

\author{
Isaac A. Friedman \\ Henrietta Szold Institute, The National Institute for Research in the Behavioral Sciences, Jerusalem, Israel \\ Email: isaac685@gmail.com
}

How to cite this paper: Friedman, I. A. (2020). The Competent School Principal: Personality Traits and Professional Skills. Psychology, 11, 823-844.

https://doi.org/10.4236/psych.2020.116054

Received: May 5, 2020

Accepted: May 31, 2020

Published: June 3, 2020

Copyright $\odot 2020$ by author(s) and Scientific Research Publishing Inc. This work is licensed under the Creative Commons Attribution International License (CC BY 4.0).

http://creativecommons.org/licenses/by/4.0/

(c) (i) Open Access

\begin{abstract}
Purpose: The purpose of the present research was to study school principals' perceived sense of professional self-efficacy, in an attempt to unveil its unique components, and to substantiate a Traits-Skills conceptualization of a competent school principal. Design: 550 serving school principals filled out a self-report questionnaire, which contained items describing common school principals' tasks and routine assignments. Respondents reported how well they were able to execute each of those tasks or assignments under restricting circumstances. Facet Theory was the methodological approach for designing the study and data processing, using Smallest Space Analysis. Findings: The study provided empirical evidence in support of the Traits-Skills conceptualization of a competent school principal comprising 1) Four traits: Intrapersonal human ability; Inter-personal (social) human ability; Strategic intra-organizational (conceptual) ability; and Inter-organizational (political) strategic ability, and 2) Five administrative skills: General management; Staff management; School general leadership; Instructional leadership; External relations. Originality and Social Implications: The Traits-Skills conceptualization of the competent principal can be instrumental in bringing about an analytical view of principals' sense of professional self-efficacy. It can also serve as a guide to selecting candidates for principalship positions and to their training.
\end{abstract}

\section{Keywords}

School Principals, Personality Traits, Professional Competence, Managerial Skills, Self-Efficacy, Facet Theory

\section{Introduction}

Leadership and management are essential for effective functioning of a school, and the larger and more complex schools are, the greater the importance of the 
integration between leadership and management, especially in contemporary times of swift environmental, social, and economic changes (Gardner, 1990; Kellerman, 2004; Kotter, 1990; Organ \& Bateman, 1991). School principals should therefore possess high professional competence as leaders and managers jointly. A pivotal question in this matter is what is the meaning of contemporary school principals' professional competence as leaders and managers? The extensive literature in the field of leadership and management in general, public and private enterprise organizations has been dealing with this question for several decades, and educational administration theorists have been trying to adapt and modify the knowledge and expertise originating in this literature to school administration (Hogg, 2010; Northfields, 2014; Rollinson, 2002).

The purpose of the present study was to identify the components of school principals' sense of professional self-efficacy, conceived by serving experienced and novice principals. An attempt was made to define the sense of professional competence components, which are unique to school principals, not just as an adaptation of general managers' conception of self-efficacy, as defined by Bandura (1997). A particular notice was taken of serving school principals' point of view in order to attain a more realistic view of this important concept. The first part of this article presents a tentative conceptual model of school principals' professional competence termed "The Traits-Skills Professional Efficacy Conceptualization" (in short: "Traits-Skills Efficacy-TTE"). The second part of the article presents a study providing empirical evidence in support of the TraitsSkills Efficacy (TTE) conceptualization validity. Facet Theory, which integrates research design and data analysis, was used in this study.

\section{Theoretical Framework}

\subsection{Personality Traits, Abilities, Skills, and Competence}

The concept of personality traits was used to denote consistent patterns of behavior, especially expressive or stylistic behavior (Gunter, 2019; Winter, John, Stewart et al., 1998). Personality trait theory states that individuals can be characterized in terms of relatively enduring patterns of thoughts, feelings, and actions; that traits can be quantitatively assessed; and that they show some degree of cross situational consistency. Traits point to more or less consistent and recurrent patterns of acting and reacting, that simultaneously characterize individuals and differentiate them from others, and they allow for the discovery of empirical generalizations about how others with similar traits are likely to act and react (McCrae \& Costa, 2008: p. 160). The trait perspective is based on a set of assumptions about what people are like and what a theory of personality ought to do. Personality traits may be regarded as dispositional, describing assumingly internal, stable, and global individual differences in behavior, thought and feeling (McAdams \& Pals, 2007). Ability is defined as the individual's potential of performing a physical or mental activity that can stem from an inborn talent, which is a dispositional personality trait, which describes or determines the in- 
dividual's behavior over a broad range of situations and roles. Ability may serve synonymously to intelligence (Colman, 2001). Skill is defined as expertise or proficiency that is acquired through training and experience (guidance and direct or indirect experience) which creates a practical possibility for a behavior or structured action patterns in order to achieve a goal (Colman, 2001). Competence is the entire repertoire of the person's abilities, which are implemented when fulfilling roles or a group of tasks (VandenBos, 2006).

It is conceptually sensible to sketch the structure and relationships of traits, abilities, skills, and competence in a hierarchical order, where personality traits are basal, followed by abilities and skills, culminating in competence. Traits are usually located at the subconscious level, whereas abilities and skills are expressed at the overt level of behavior. Competence may also be expressed at the behavioral level, is context-dependent, and when referring to professionals who act within the framework of an organization, it is dependent on the organizational environment and defined in terms of results based on commonly accepted standards. Spencer \& Spencer (1993) illustrated the relation between personality traits, skills and competence as an iceberg, at whose base (which is immersed deep underwater) are personality traits, motives, the role and the social image. Above them are the skills (some of which are seen on the surface, and most of which are sunken underwater), and only the competence is seen entirely above water.

\subsection{Leaders and Managers' Personality Traits and Abilities}

Social psychology has attempted to study and explain the leadership phenomenon meaning in terms of personality traits and abilities, which turn one person into a more effective leader, and another into a less effective one. Research in this domain has for many years tried to uncover the typical traits and characteristics of managers in industrial and public organizations (Organ \& Bateman, 1991). Indeed, from the beginning of the twentieth century until the end of World War II, research on the personality traits of leaders comprised a pivotal element in the theory of leadership, where the main effort was to identify differences between personality characteristics of leaders and their followers in different organizational systems (cf, Northouse, 2013 and of course, Stogdill, 1974). Research into the traits of leaders and managers indicated that personality traits and characteristics, which were identified as leadership pertinent, did indeed characterize leaders, but not sufficiently enough for explaining the creation and consolidation of leadership among certain people, and its absence among people who are not leaders. Following World War II, leadership research tended towards the study of behavioral patterns of leaders, and leadership was regarded as a process and not as a personality trait. Nonetheless, the issue of personality traits of leaders was not entirely abandoned, and the abilities of leaders and managers as well as their training, skills and behavior patterns have now been underscored (Avolio, Sosik, Jung, \& Berson, 2003; Chin, 2015; Marshal-Mies, 
Fleishman, Martin, Zaccara, Baughman, \& McGee, 2000; Purdie, 2014).

Although leadership traits theory has been criticized for many years, and current thinking claims that while there are no universal leadership traits, there are traits critically important in certain types of leadership situations (LePine, Hollenbeck, Ilgen, \& Hedlund, 1997; Taggar, Hackett, \& Saha, 1999). Jirasnghe and Lyons (1996), indicated that most of the managerial and leadership traits which were related to success at work were in fact dimensions of personality more than of skills. Therefore, they have suggested, as proposed decades earlier, that some people possess personality traits or characteristics, which enable them to be competent leaders, while others do not. Within this framework, two major traits were found to be important for leadership: 1) The ability to sense and discern the demands and requirements of familiar and unfamiliar situations, and 2) abilities that enable the person to adapt him or herself to changing situations (Rollinson, 2002).

\subsection{Leaders and Managers' Technical, Human and Conceptual Skills}

Cherniss (1993) proposed an approach to the classification of managerial skills in terms of a taxonomy that includes three skills in similar versions by Katz (1955), Mann (1965) and to some extent. Katz referred to skills as ability demonstrated in performance, which is not necessarily inborn and therefore can be imparted. He argued that effective management stems from three basic skills, which he termed technical, human and conceptual skills. Cherniss (1993), who defined organizational efficacy as the ability to influence the social or political forces within the organization and view the organization as a holistic single entity, formulated a viewpoint very similar to Katz's. Yukl (1998) indicated that some researchers discern a fourth skill, the administrative skill, defined in terms of the ability to perform a particular type of administrative functions or behaviors, such as planning, organizing, delegating authority, negotiating, instructing, and managing meetings.

\subsection{School Principals' Basic Leadership and Administrative Competencies}

In the education literature, the principal is perceived as a leader, whose leadership depends on personal traits, and not only on acquired professional skills and knowledge that are related to the execution of his or her managerial tasks (Berkovich \& Eyal, 2015; Bogler, 2000; Gawlik, 2018; Judge, Bono, Ilies, \& Gerhardt, 2002). School principals are positioned at the head of the organizational pyramid; they carry the burden of the pedagogic leadership and organizational wellbeing of the school (Aberg, 2014; Leithwood, Harris, \& Hopkins, 2020; Maxwell \& Reiley, 2016; Robbins \& Judge, 2009). School principal leadership is essential, and myriad of studies have dealt with the leadership perspective of the effective principal (Beare, Caldwell, \& Millikan, 1994; Edmonds, 1981; Reid, 
Hopkins, \& Holly, 1988; Sammons, 1999; Sebastian, Allensworth, Wiedermann et al., 2019). Jirasinghe \& Lyons (1996), for example, suggested that school principals' competence may be expressed in the following five areas: 1) Planning and administrative processes (management and leadership: analysis, planning, leadership guidance); 2) Care of people (human relations: sensitivity, motivation, appreciation); 3) Managing the political environment (external relations: political and persuasive ability, managing negotiation); 4) Professional and technical knowledge (pedagogy); and 5) Personal skills (commitment and values, reasoning and judgment, self-awareness and self-development, radiation of positive image and communication). The National Association of Secondary School Principals in the US defined 12 competence aspects in performing the principalship role (problem solving, judgment, organizational ability, decisiveness, leadership, sensitivity, range of interests, personal motivation, educational values, stress tolerance, verbal oral communication, written communication) (presented in Jirasinghe \& Lyons, 1996: p. 138). These aspects were also saliently found in studies by Brama (2004) and Friedman \& Brama (2010), who accentuated that principals' leadership is expressed in both the administrative and the pedagogic school functioning arena. Pedagogic ability may be classified as the principal's technical skill, and human relations may, obviously, be classified as human skills as defined by Katz (1955). School principals usually observe the school with a systemic view, which encompasses the school and its physical, social and economic environment as an open, integrative system possessing various components (Glatter, 1989; Handy \& Aitken, 1990; Sakis, Ekinci, \& Sarican, 2019). Such observation can be classified as a conceptual or strategic skill as proposed by Katz (1955).

\section{A Traits-Skills Conceptualization of School Principals' Efficacy}

Following a large-scale study involving individual in-depth interviews and taskforce groups of serving experienced and novice school principals, Friedman \& Brama (2010) have put forward a tentative trait-skills conceptualization of school principals' sense of professional self-efficacy. They indicated that principals' perception of professional self-efficacy could be clustered into two conceptual groups: general and specific function tasks. Efficacy of general function tasks refers to the principals' assessment of their potential performance abilities, in assignments that are not directly related to managing educational organizations (non-job-specific related abilities), and may be defined "general abilities". Perceptions regarding efficacy of specific tasks are related to the unique work carried out in a specific organization, i.e. schools, defined in terms of work assignments (job-specific related abilities). Such assignments are regarded as unique skills required of a particular profession or occupation, and may be defined as "specific abilities". These perceptions prompted Friedman \& Brama (2010) to suggest that school principals' professional self-efficacy may be defined as a 
joining of two conceptual sets: Personality traits (general abilities, or intelligences, that are usually non-job-specific related) and skills that are focused either on job-specific (educational) or non-job-specific assignments. They have also suggested that school principals' perception of leadership includes intrapsychic abilities (of the principal towards him or herself) and inter-psychic abilities (which emanate skills that enable leading and guiding other people). In addition, they differentiated between two significant factors in the principals' sense of professional self-efficacy, where each comprises two elements: 1) Relations: sense of possessing abilities to a) treat employees as humans, and b) to lead and instruct employees as role holders; and 2) Task. sense of possessing abilities required for a) goal-directed leadership (conscientiousness: achievement strivingstrong sense of purpose and high aspiration levels), and b) performance-activation and control of the professional work environment.

The elements of Friedman and Brama's traits and skills conceptualization of efficacious school principals can be delineated as follows (see Figure 1).

\section{1) Dispositional Personality Traits}

Efficacious principals may be characterized by four specific dispositional personality traits that converge into two clusters: 1) Human abilities: a) intra-personal ability and b) inter-personal (social) ability and 2) Strategic abilities: a) intra-organizational ability and b) inter-organizational (political) ability. The human abilities represent the relations aspect and the strategic abilities represent the task aspect of leaders' (and principals') function, as expanded below.

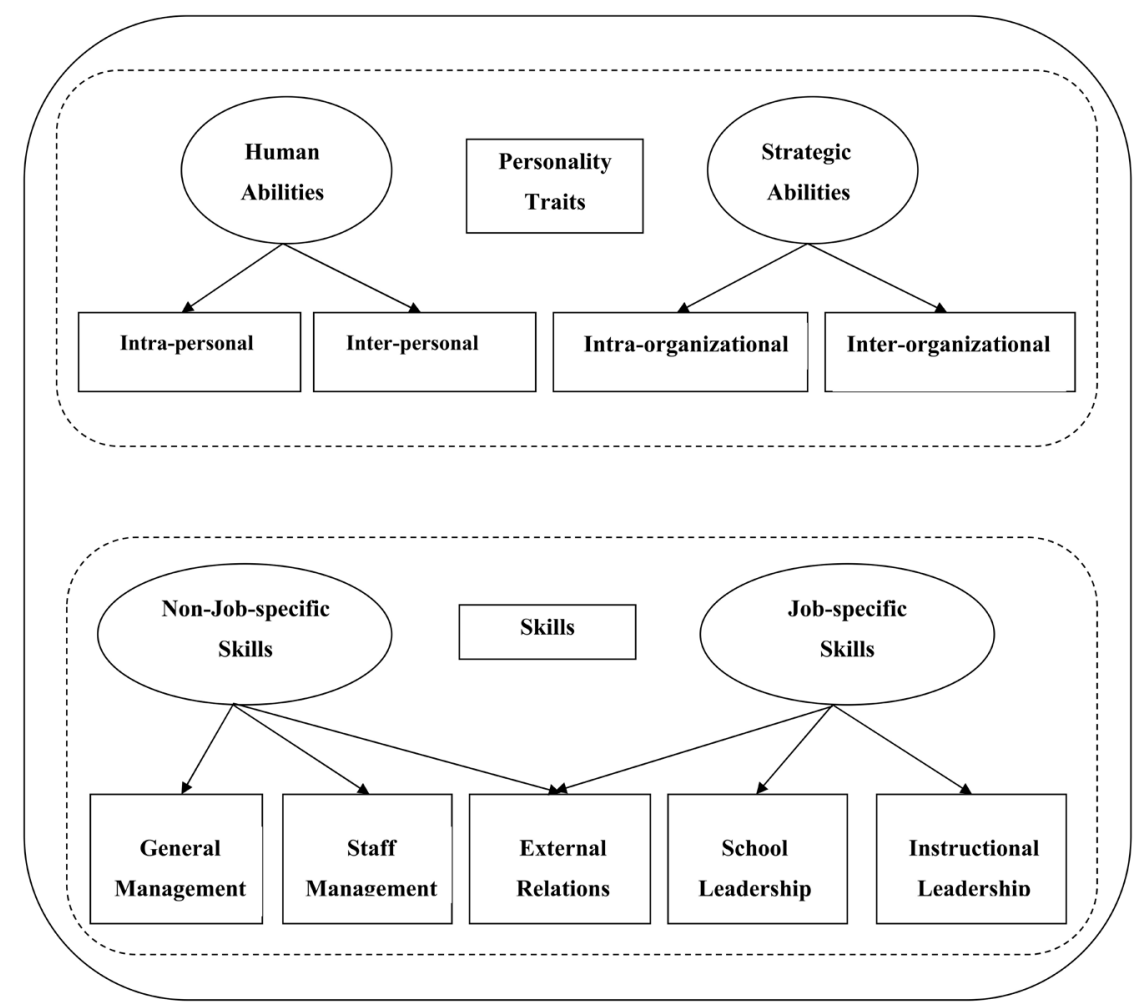

Figure 1. A traits-skills conceptualization of efficacious school principals. 


\section{a) Human abilities}

\section{i) Intra-personal ability}

Intra-personal ability is the person's accessibility to his or her own emotional life: the ability to differentiate between different emotions, label them, give them symbolic codes and rely on such codes in order to understand and direct his or her own behavior. The intra-personal goal enables a person to expose and classify groups of complex and distinct emotions (Gardner, 1985: p. 239).

ii) Inter-personal (social) ability

Inter-personal ability is the ability to understand and internalize the feelings, thoughts and intentions of other people (O'Sullivan, Guilford, \& deMill, 1965), to differentiate and distinguish between different people, especially in everything related to their mood, temperament, motivation and intentions. Inter-personal ability enables the person to recognize the intentions and aspirations of those around him or her, even when these intentions are inconspicuous, and to act according to these recognitions. This ability is based, firstly, on recognizing situations in which it is necessary to help others, activate them and supervise their work, or to protect the organization. This ability is, to a great extent, a natural trait which also requires knowledge (Drasgow, 2003: p. 123; Flavell, Botkin, \& Fry, 1968). Inter-personal ability is prominent among leaders, managers, politicians, spiritual and religious leaders, experienced parents, teachers, as well as among people in the field of help professions (caregivers, consultants, human service providers) (Gardner, 1985: p. 239). Inter-personal ability is also a social ability, and some refer to it as "social intelligence" (see Golman, 2009).

Manifestations of inter-personal (social) ability usually are: 1) Emotional expressiveness: ability to broadcast and radiate feelings and attitudes; 2) Emotional sensitivity: ability to decipher emotions, beliefs or attitudes of others, or cues pertaining to power struggles; 3 ) Social expressiveness: ability to express yourself in society and initiate a conversation in the group; 4) Social sensitivity: ability to understand sayings and expressions of others and recognize social rules and norms; 5) Emotional control: ability to regulate emotional communication and control body language; 6) Social control: self-representation-a behavior directed towards presenting information that describes a unique image of the self to other people (Gross, 1998; Gross, Richards, \& John, 2006; Gross \& Thompson, 2007; Riggio, 1986; Tamir, Mitchel, \& Gross, 2008).

Inter-personal (social) ability was found to be in high correlation with emotional intelligence as defined by Salovey \& Mayer (1990).

\section{b) Strategic abilities}

Strategic abilities are general analytic, comprising logical thinking and conceptualization of complex relations, creativity when formulating ideas and solving problems, abilities to understand and analyze events inside and outside the organization, discern trends, anticipate changes, and recognize opportunities and potential problems (Katz, 1955). Strategic abilities constitute two aspects: 1) intra-organizational and 2) inter-organizational. 


\section{i) Strategic intra-organizational ability}

Strategic intra-organizational ability is portrayed in understanding and analyzing events within the organizational framework, distinction between directions, connections and relationships within the organization (Katz, 1955). It is also expressed in influencing the social or political forces within the organization, and in viewing the organization as a system. This ability includes understanding how the different functions in the organization are related to and dependent on each other, and how changes in one part of the organization affect its other parts (Cherniss, 1993).

ii) Strategic inter-organizational ability

Inter-organizational strategic ability is manifested in a capacity to comprehensively view the components of the goals, the policy and the actions of the organization in the political, social and public context of the organization's environment. This ability is expressed in understanding and analyzing events which originate outside the organization and its surroundings, and understanding their effect on the organization itself. It is also expressed in an influence of the social or political forces that function in the organization's environment (community, political, economic and social environment) as a as a system (Cherniss, 1993). This ability leads to making strategic decisions regarding the proper inter-organizational relations, interrelations with the environment and an attempt to comply with the needs of the environment and its desires. It may also be termed environmental-political organizational ability.

\section{2) Skills}

The professional skills of efficacious principals include 1) non-job-specific related skills (general managerial skills that do not necessarily pertain directly to managing schools): General management (administration): running the school as an administrative organization; Staff management: directing the school's staff; External relations: initiating and maintaining interrelationships with the school community; 2) job-specific related skills (pertaining specifically to schools): School leadership: leading the school as an educational organization; and Instructional leadership: directing the school pedagogy.

The professional skills are described in some detail below.

\section{a) non-job-specific related skills}

\section{General management}

General management is a non-job-related skill that refers to the ability to manage an administrative organization, such as identifying needs, planning, setting goals, preparing a work plan, making decisions, sharing in decision making, delegating authority, control and monitoring, performances (actually performing the decisions and plans), coordination, affording feedback to workers and motivating them to excellence.

\section{Staff management}

The principal can refer to the school's staff as "people" and as professional role-holders. There is a distinction between directing people as professionals- 
which is part of general management and leadership (such as motivating workers, the principal serving as role figure who sweeps the staff with his or her ideas, and evaluating the professional work), and aspects of treating employees as "people", which belongs to the human relations abilities. Within this framework, principals must enable accessibility and sensitivity (a principal with high sense of self-efficacy in the field of human relations enables convenient access to him or her), and professionalism together with humanity, skills for a humane attitude towards individuals with whom principals interact during their work.

External relations

External relations within the framework of the school principal's function have been awarded special attention in recent years, together with the development of the dominant outlook in all fields of management that views the organization as a link in a social chain, as a system open to influences, influencing its environment (Crow, Hausman, \& Scribner, 2002; Michel, 1995). Today's principals do not shut themselves up with their team behind the school walls and cannot disengage themselves from their surroundings. In this age of decentralization of authority, resources and responsibility, together with parents' possibilities for choice and the development of active local communication, principals fill an active role in the relations between the school and its environment. External relations may be classified as a non-job-specific related skill, since it can be perceived as part of general management inventory skills. However, that skill is surely located on the border line between general management and school management required skills.

\section{b) job-specific related skills}

\section{School leadership}

The skills related to school leadership are mainly those of communication, which include a practice of affording convincing explanations and reasoning for decisions; skills of evaluating existing situations and crystallizing predictions for setting the school vision for the achievement of high and challenging goals; skills for encouraging compliance of the team for following the leader and achieving the goals which he or she sets for them; skills of making decisions at the strategic level, and especially cooperating with role holders in the school's intra-organizational processes.

\section{Instructional leadership}

Pedagogy makes the difference between managing a school and managing any other service organization. This is a singular professional aspect that necessitates acquaintance with the unique contents and processes of the school as an educational organization, which is responsible for learning and education. This aspect of the management role can be viewed in most descriptions of the of school principals' tasks. Friedman and Brama identified two dimensions of this component: 1) directing teaching assignments; 2) guiding the teaching staff. In this context the principal must be able to prompt for advancing school curricula and using diverse teaching and evaluation methods. This ability entails the need to 
be familiar with innovations in the field of pedagogy and to integrate them in the school. In the domain of directing the teaching stuff, the principals lead staff members who carry out the teaching and educating assignment by the power of their professional authority. A principal with a high sense professional self-efficacy is able to carry out professional evaluation of the teachers' function and supply them with useful and concrete feedback on their work.

\section{Empirical Evidence in Support of the Traits-Skills Efficacy (TSE) Conceptualization}

\subsection{Research Goals, Definitions and Hypotheses}

The goal of the study was to test for the validity of the competent principal's Traits-Skills model, presented in Figure 1, based on Facet Theory methodological approach. The first stage of a research performed based on Facet Theory is to define the facets of the concept or the phenomenon under study (Borg \& Shye, 1995; Guttman, 1959). Facets characterize modes of behavior or action, or links, where each facet contains several elements (Borg \& Lingoes, 1987; Maslovaty \& Levy, 2001; Shye, Elizur, \& Hoffman, 1994). Based on Friedman \& Brama's (2010) conceptualization school principals' sense of professional competence was defined as a single facet (Facet A: Sense of competence), containing two elements. The first element represented specific personality traits (abilities) and the second represents skills. The Personality traits element includes: 1) Human abilities: a) intra-personal and b) inter-personal (social); 2) Strategic abilities: a) intra-organizational and b) inter-organizational (political). The Skills element comprising this facet includes the following skills: 1) General management of the school (as an administrative organization); 2) Staff management; 3) External relations; 4) School leadership; and 5) Instructional leadership.

It was postulated that a clear hierarchic relation exists between the two elements in Facet A. Personal traits abilities serve as a necessary (or at the very least desirable) basis for the creation of skills: if we added professional knowledge and professional experience, along with the characteristics of the role to the traits, we might obtain unique performance skills. A professional skill is thus composed of pertaining specific traits (as a base level), along with experience and knowledge (as an upper level). Therefore, items constituting the skills element, which contain unique attributes, experience and expertise, express a high level of complexity. Facet $\mathbf{A}$ is therefore of a quantitative nature, in the sense that the items included in its elements differ from each other in quantity (and not in quality), which is the addition of elements. The inter-correlations among the components of the personality traits element may possibly not be high: a principal can feel "strong" in one skill, but not necessarily so in another. The skills included in the performance-implementation element may be a highly cohesive unit, since an integrative system of activities is mandatory for running a school. The correlations and the similarity between the items that compose this element may therefore be particularly high. 


\subsection{The Research Hypotheses}

The research hypotheses were:

1) Item dispersion on the Smallest Space Analysis (SSA) map will take the form of two concentric circles in which the first element items (traits) will comprise the first, or core, concentric circle, and the items of the second element (skills) will comprise the second concentric circle. A clear distinction is expected to be between personality traits (abilities) and professional skills.

2) The traits items group will be comprised of four clearly distinct spatial regions: a) Intra-personal, and b) Inter-personal human abilities; c) Intra-organizational, and d). Inter-organizational (political) strategic abilities. Intra-organizational, and Inter-organizational items regions will be located adjacently on the SSA map, thus forming together a larger region of strategic abilities

3) The Skills items group will comprise five clearly distinct spatial regions: a) General management; b) staff management; c) Instructional leadership; d) school leadership; and e) external relations. General management and staff management items regions will be located adjacently on the SSA map, thus forming together a larger region of non-job specific skills. Instructional leadership, school leadership, and external relations items regions will be located adjacently on the SSA map, thus forming together a larger region of job (school) specific skills.

\section{Method}

\subsection{Sample}

The sample included some 550 school principals of elementary, junior and high schools serving at all stages of schooling during the 2003-2004 school academic year. The participants were not sampled using statistical sampling procedures, but were chosen to represent principals from the entire country, from all sectors and types of schools. The analyses reported in the present article were based on 538 subjects, which included: 177 men (32.9\%) and 348 women (64.7\%), with a mean age of 47.3 years ( $\underline{\text { SD }} 6.9$ ), mean seniority as principal 10.4 years ( $\underline{\mathrm{SD}} 8.0$ ); 402 (74.4\%) were principals of elementary schools, 119 (22.1\%) were principals of post-primary schools and $8(1.5 \%)$ were principals of schools with first to twelfth grades; 470 (87.3\%) were from the Jewish sector (298 from the national education and 172 from the national-religious education) and 68 (12.6\%) were from the Arab sector. The sample was thus diverse in terms of the principals' background variables and in terms of the nature of the school which they were heading.

\subsection{Instrumentation}

The instrument was a self-report questionnaire. The questionnaire items were collected by thorough and extensive interviews of dozens of serving principals, who were asked to describe the patterns of behavior and action, which define a "good" principal. The interviews were content analyzed and yielded dozens of 
items. The questionnaire items were selected at random from this item pool. It can be stated with a reasonable degree of confidence that the items included in the questionnaire fairly represent serving principals' views of a good principal's characteristics, abilities and behaviors.

The questionnaire contained 57 statements, which were divided into five sections, utilizing three judges' evaluations (see Table 1). Respondents were asked to report how well they believed they were able to successfully execute each of those tasks or assignments under restricting circumstances. The optional response range was on a scale of 1 through $7(1=$ not able at all; $2=$ to a very small extent; $3=$ to a small extent; $4=$ to a moderate extent; $5=$ to a great extent; $6=$ to a very great extent; $7=$ certainly able). The questionnaire was validated repeatedly (Brama, 2004).

Table 1. Items representing school principals' characteristics, and behaviors, as depicted in Figures 2-4.

Items of the outer concentric circle, that represent specific personality traits

Intra-personal human ability

50. To restrain oneself over anger at work

51. To overcome the fear of failure when you are beginning something new

49. To observe yourself, to recognize your weaknesses and treat them in order to improve your function

46. To enable introduction of changes initiated by teachers

57. To communicate well and to the same extent with a minor official and with a powerful senior agent

39. To motivate the teachers to work out of a feeling of spiritual-conceptual commitment and not only by force of rules and regulations

41. To persevere in the performance of a plan over time, even if you do not see immediate results

43. To act in the school in a way that seems correct to you, even if it is not customary and is not absolutely compatible with dictates

Inter-personal human ability

16. To be accessible and available at all times to pupils, teachers and parents

15. To solve conflicts between people by activating all of your authority

12. To be attentive and caring for the personal problems of the members of the team

17. To carefully listen to what the child has to say

13. To listen to distresses, complaints and comments of parents

24. To be friendly to people and at the same time uncompromising in your demands of them

21. To support people and be sensitive towards them, without being regarded as being too lenient at work

Strategic intra-organizational ability

2. To find and understand the common denominator of all the different things that take place at the school

1. To test and examine numerous and different possibilities for action before you begin

3. To identify the needs of the environment (the community) of the school in order to formulate a

school vision that is compatible with it

5. To plan your work week so that you will have time for things that are important to you

4. To set clear goals for achievement from the team and from the pupils

25. To comment to a teacher who is not fulfilling his or her role as required

Inter-organizational strategic ability

32. To act for recruitment of funds and contributions for the school from different sources

56. To market the school

53. To disseminate successful ideas that were developed in your school in professional forums

54. To identify innovations that are customary in other schools and to bring in-service training to your school in order to implement them 


\section{Continued}

Items of the inner concentric circle that represent skills

Team Management-directing the school's staff (non-job-specific related)

19. To enable a large part of the team to participate in decision-making processes

20. To delegate significant authorities to teachers in important issues

22. To develop the professional ability of the weaker members in the team

23. To provide team members with useful and detailed feedback on their work

18. To motivate the team members to achieve excellence

General Management-running the school as an administrative organization (non-job-specific related)

38. Preparing an annual work plan that includes a compatible budget

6. To prepare work plans for the school for a range beyond the current school year

7. To plan the assignment of manpower, roles, authorities and resources in the school

9. To activate an effective mechanism of control and monitoring of performance of decisions made

8. To carry out plans and decisions made

42. To find the balance between the demands for immediate action and "improvised solutions" and dealing in pre-planned programs

10. To make decisions through a process of systematic consideration Instructional leadership_-managing the school pedagogy (job-specific related)

36. To serve as a source of knowledge in the fields of pedagogy for the teachers

33. To be involved in advancing the preparation of school curricula

35. To use diverse evaluation methods in the school

34. To employ diverse teaching methods in the school

37. To perform professional evaluation of the function of the teacher

School leadership-leading the school as an administrative organization (job-specific related)

52. To raise new and creative ideas for running the school

29. To influence people to change their opinion or actions and act in a way desirable to the leader

48. To set high and challenging goals for yourself

55. To manage the school such that everyone can follow the processes, decisions and appointments

47. To set achievable goals for yourself and to examine whether you met them

44. To act with enthusiasm and to sweep the team after you

40. To persuasively explain and give reasons for your decisions and instructions

External Relations-interrelationships with the school community (job-specific related)

27. To encourage initiatives for collaboration between the school and the community

28 . To contribute to the community around the school by active involvement

26. To develop good relations with people in the community and in the local authority, for the benefit of the school

30. To present your demands to different entities and to achieve what is right of the school to receive

31. To handle conflicts related to the relations between the school and its environment and to lead to their satisfactory solution

\subsection{Procedure}

The original idea for the present research was crystallized in a previous study (Brama, 2004; Friedman \& Brama, 2010), in which serving principals with different levels of seniority from different schools expressed their feelings and account of their professional self-efficacy. Content analyses of the principals' responses, based on the underlying theoretical background, brought about a conception of principals' perception of professional competence. The present study used existing data.

\section{Results}

In the first stage of data analysis correlations (monotonicity coefficients) were 
calculated between items, and a correlations matrix was calculated. In the second stage, smallest space analysis (SSA) was performed based on the calculated correlations matrix, using HUDAP (Hebrew University Data Analysis Package).

\subsection{The Concentric Pattern of Item Dispersion on the SSA Map (Hypothesis 1)}

Figure 2 depicts the variables deployment on the SSA map, which represent the principals' perceptions of their professional competence. The coefficient of alienation $(\mathrm{COA})^{1}$ was 0.16 , which is considered a very good fit between the calculated correlations matrix and the graphic presentation of the variables on the item deployment map. The goodness-of-fit coefficient ${ }^{2}$ of the data deployment was 1.00 (which represents a perfect fit).

The general structure of the data deployment in Figure 2 is concentric, comprising two concentric circles (this is the radial aspect of the data deployment). The inner circle contains the skills items, and the outer concentric circle contains the personal traits (the ability potential) items. Figure 2 clearly shows that items which are located close to the origin of the circular structure are grouped closely together, representing high correlations between the items scores. A high correlation between items scores points to a great extent of semantic nearness between the items. Items which are located farther from the origin of the circular structure and closer to the periphery are more dispersed (such pattern represents low correlations among item scores, which is indicative of low semantic proximity and a greater distinction between the contents of the items, where each item is significantly "different" from the others). The items located in the periphery of the SSA map also represent concepts or phenomena that are different from those at the origin of the radial deployment. The items in each of the two circles were classified according to their content, as defined by the elements of facet $\mathbf{A}$. The boundaries between the two circles are marked according to the two elements of facet $\underline{\text { A }}$ (see hypothesis 1 ).

\subsection{The Internal Structure of the Concentric Circles (Hypotheses 2 and 3 )}

Smallest Space Analysis (SSA) was then performed for the scores of each of the two concentric circles.

1). the internal structure of the peripheral circle (hypothesis 2)

In Figure 3 we see that all the human abilities items are positioned at the left

${ }^{1}$ The coefficient of alienation (COA) is a technical term that expresses the extent to which the physical distances between the items in the SSA map truly reflect (inversely proportional) the set of correlations between them, i.e. the extent to which the software succeeded in "arranging" them in the best graphic manner. The range of values of the COA is from 0 to 1 , and the lower the value of the $\mathrm{COA}$, the better the fit. COA values of less than 0.20 are usually preferred, but values somewhat higher are accepted as reasonable.

${ }^{2}$ The goodness-of-fit measure expresses the extent to which the obtained empirical structure reflects the hypothesized content facets, i.e. the congruence between the tested theoretical model and the spatial deployment of the empirical data. The range of values of the goodness-of-fit measure is between 0 and 1 , and a higher value indicates a better fit. 
hand side of the SSA map, and all the strategic abilities items are positioned at the right hand side of the map (see Figure 3 and Table 1). The human abilities region of the map is divided into two sub-regions: lower and upper. Intra-personal human ability items are located at the lower region, and inter-personal (social) human ability items are located at the upper left. Results indicated an almost perfect fit with the classification of the items as detailed in Table 1, except for one item: item 25 was located in the sector of the strategic intra-organizational ability, whereas it should have been located in the inter-personal (social) ability sector.

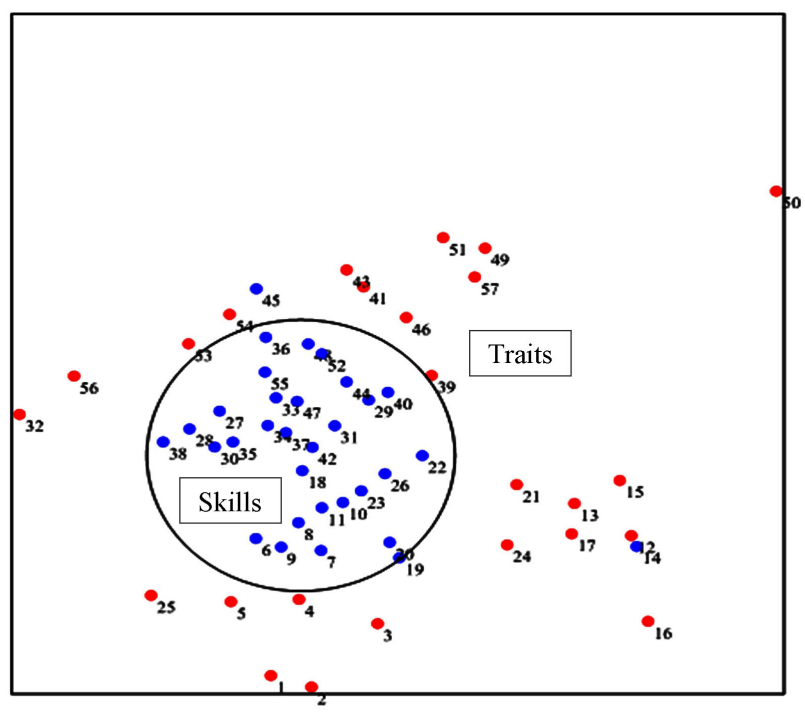

Figure 2. Components of the professional competence of the school principal. (Facet A) data deployment on the SSA map in a two-dimensional presentation.

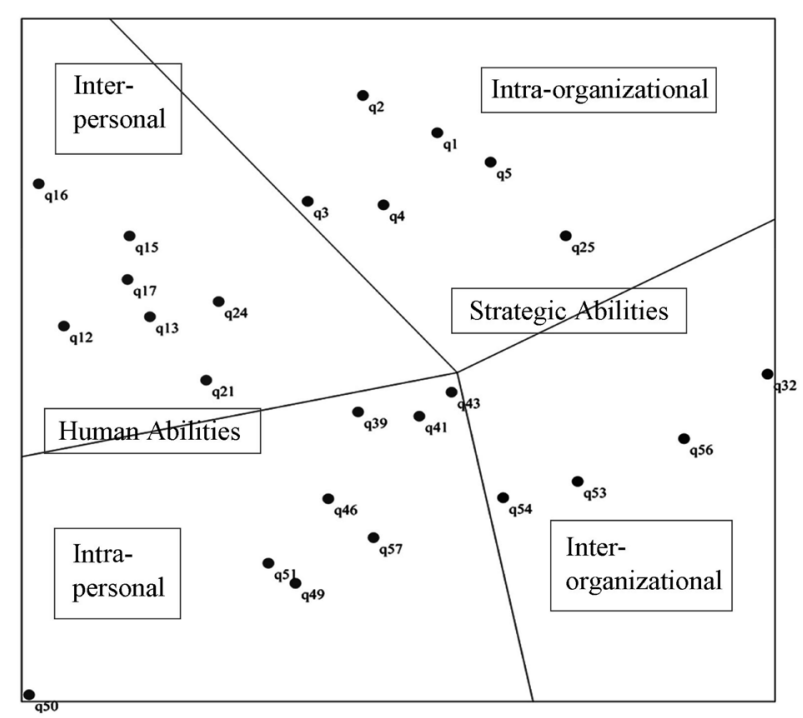

Figure 3. Items of the peripheral (outer) circle, which represent personality traits: data deployment on the SSA map in a twodimensional presentation. 
- Intra-personal human ability. Expresses socio-emotional stability, self-monitoring or self-regulation. It comprises reflectivity, self-confidence, persistence, conceptual independence, overcoming anger at work, looking into oneself, knowing one's weaknesses and treating them for improving one's function, overcoming the fear of failure, persevering in performing a program over time even when the outcomes are not immediately apparent, acting in a way one sees fit even if it is not customary and is not compatible with external dictates.

- Inter-personal (social) human ability. Expresses mainly assertive humanity. Being accessible and available to anyone needing it, attentive and caring, nice to people and at the same time uncompromising in demands of them, sensitive and supportive without being regarded as too lenient.

The strategic abilities region of the map is also divided into two sub-regions: lower and upper. Inter-organizational (political) strategic ability items are located at the lower right side of the map, and intra-organizational strategic ability items are located at the upper right side of the map.

- Inter-organizational (political) strategic ability. Includes the ability for initiating and maintaining relations between the school and its environment. Recruiting funds and contributions, marketing the school, disseminating successful ideas that were developed at the school and identifying innovations introduced in other schools and importing them to the school for implementation.

- Intra-organizational strategic ability. Includes mainly strategic thinking. Finding and understanding the common denominator of things that take place in the school, setting clear goals for achievements by the team and by the pupils, identifying the needs of the school's environment, examining numerous and diverse possibilities for action before starting any action.

2). the internal structure of the inner circle (hypothesis 3 )

Figure 4 depicts the deployment of variables in the inner circle (skills). The items in this circle comprise 5 groups of topics, which represent five role skills. The regions are clearly detectable in Figure 4. Each region represents skills required of principals in order to effectively manage and run a school (see Table 1 and Figure 4):

- General management: Planning manpower; making decisions; control; coordination; fulfilling roles and responsibilities.

- Staff management: Enabling the team to participate in decision making; providing feedback to the team; cultivating and advancing the team; motivating; delegating authority.

- External relations (initiating and maintaining interrelationships with the school community): Developing relations with people in the community and the authorities; encouraging initiatives for collaboration; effective handling of community conflicts; assertive and determined application to external entities for school needs. 


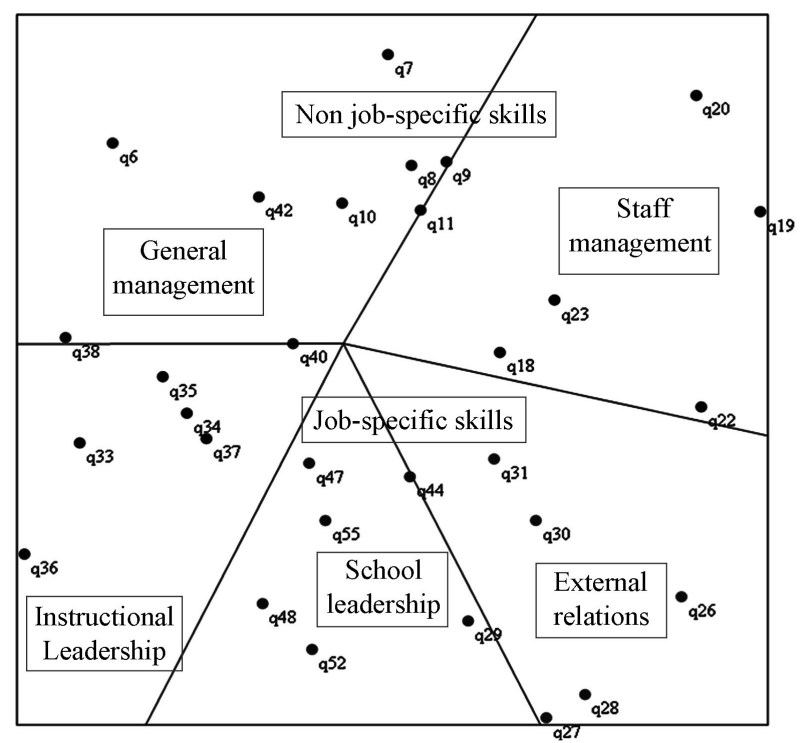

Figure 4. Items in the inner circle that represent skills of the role: data deployment on the SSA map in a two-dimensional presentation.

- School leadership: Creating new and innovative ideas for running the school; charismatic effect on people; setting high goals and targets for achievement at the school and monitoring their achievement.

- Instructional leadership: promoting pedagogic knowhow to the teachers; advancing the preparation of a school curriculum; professional evaluation of the teachers' work; activating diverse teaching and evaluation methods in the school.

Results indicated an almost perfect fit with the classification of the items as detailed in Table 1, except for one item: item 25 was located in the sector of the strategic intra-organizational ability, whereas it should have been located in the inter-personal (social) ability sector.

\section{Discussion}

The study attempted to present school principals' sense of self-efficacy, or professional competency, as a conceptual function of traits and skills. The three research hypotheses were supported by empirical evidence produced in the present study, and therefore it can be said that the findings of the study provided empirical support to the supposition that a competent school principal may be a person characterized by 1) four traits: Intra-personal human ability; Inter-personal (social) human ability; Strategic intra-organizational ability; and Inter-organizational (political) strategic ability; and 2) five skills: General management; School leadership; External relations; Staff management; and Instructional leadership. All five skills rely, or are dependent on, to some extent on all four personality traits. It may then be argued that there are unique links or dependencies between certain abilities and certain skills, as follows: 
- School leadership skill relies especially on the intra-organizational and inter-organizational strategic ability, and on the inter-personal human ability, because emotional-social maturity comprises a foundation for the school leadership skill.

- External relations skill stems especially from the strategic inter-organizational ability and from inter-personal human ability.

- Staff management and school Instructional leadership skills rely especially on the inter-personal human ability and on the strategic intra-organizational ability.

- General management skill relies on all four specific personality abilities.

- Intra-personal human ability can be regarded as a "super" ability, since it represents the most fundamental abilities of leadership and of administration.

The Traits-Skills model of the competent principal may help in creating an analytical view of principals' sense of professional self-efficacy. Based on the Traits-Skills model, it can be said that principals' sense of professional self-efficacy may comprise two hierarchical levels: 1) sense of possessing traits, or "natural talents" for organizational and pedagogic management, and 2) sense of possessing managerial, leadership and pedagogic performance skills. The TraitsSkills conceptualization of the competent principal can also serve as a guide in selecting candidates for principals' positions and training. There are ways to assess the different levels of the abilities, and it is therefore possible to choose candidates who are characterized by high levels of these abilities for a principal's role. The process of training the chosen candidates can be based on Bandura's (1997) sources for the creation of professional self-efficacy, and the training contents can include the five skills (and of course other important topics as well).

The present study encompasses an aspect of at least one facet of school principals (and maybe managers in general) self-identity, i.e. their professional competence. From this point of view, the Traits-Skills model can serve as a way in which managers view their effectiveness in any field of occupation. In this context, it is especially interesting to see that professional skills are found at the core of the professional occupation, and therefore do not differentiate between managers, whereas personal characteristics differentiate between people. Another contribution of the present study is an empirical support for Katz's (1955) model of the three managerial skills. Katz has formulated his model based on the reality with which he was familiar (over 60 years ago, and in an organizational culture different from the one that exists in Israel), and confirmation of the structure emphasizes the importance and current relevance of the Traits-Skills model.

The conception of school principals' sense professional competence offered in this study was brought about by way of formulating a theory grounded in empirical data. Similarly to any theory that is anchored in data, we can be reasonably sure that this theory will be compatible with reality and will be able to fulfill 
its role: predict and explain behavior; advance knowledge; be usable (enable the people of action and the people in the field control of situations); afford a perspective on behavior; direct future research (Glaser \& Strauss, 1967: p. 3).

\section{Conflicts of Interest}

The author declares no conflicts of interest regarding the publication of this paper.

\section{References}

Aberg, T. P. (2014). Pursuit of the Principalship. Doctoral Dissertation, Blacksburg, VA: Virginia Polytechnic Institute and State University.

Avolio, B. J., Sosik, J. J., Jung, D. I., \& Berson, Y. (2003). Leadership Models, Methods, and Applications. In W. C. Borman, D. R. Ilgan, \& R. J. Klimoski (Eds.), Handbook of Psychology, Vol. 12 Industrial and Organizational Psychology (pp. 227-308). Hoboken, NJ: Wiley and Sons. https://doi.org/10.1002/0471264385.wei1212

Bandura, A. (1997). Self-Efficacy. The Exercise of Control. New York: W. H. Freeman.

Beare, H., Caldwell, B. J., \& Millikan, R. H. (1994). Creating an Excellent School. London: Routledge.

Berkovich, I., \& Eyal, O. (2015). Educational Leaders and Emotions: An International Review of Empirical Evidence 1992-2012. Review of Educational Research, 85, 129-167. https://doi.org/10.3102/0034654314550046

Bogler, R. (2000). Leadership and Its Implementation in Education. Tel-Aviv: The Open University (Hebrew).

Borg, I., \& Lingoes, J. (1987). Multidimensional Similarity Structure Analysis. New York: Springer. https://doi.org/10.1007/978-1-4612-4768-5

Borg, I., \& Shye, S. (1995). Facet Theory. Form and Content. Thousand Oaks, CA: Sage.

Brama, R. (2004). The Professional Self-Efficacy of the Principal: The Concept and Its Components. PhD Thesis, Jerusalem: The Hebrew University (Hebrew).

Cherniss, C. (1993). Role of Professional Self-Efficacy in the Etiology and Amelioration of Burnout. In W. B. Schaufeli, C. Maslach, \& T. Marek (Eds.), Professional Burnout: Recent Developments in Theory and Research (pp. 135-143). Washington DC: Taylor and Francis. https://doi.org/10.4324/9781315227979-11

Chin, R. (2015). Examining Teamwork and Leadership in the Fields of Public Administration, Leadership, and Management. Team Performance Management, 21, 199. https://doi.org/10.1108/TPM-07-2014-0037

Colman, A. M. (2001). Dictionary of Psychology. Oxford: Oxford University Press.

Crow, G. M., Hausman, C. S., \& Scribner, J. P. (2002). Reshaping the Role of the School Principal. In J. Murphy (Ed.), The Educational Leadership Challenge: Redefining Leadership for the 21st Century. One Hundred-First Yearbook of the National Society for the Study of Education (pp. 15-43). Chicago, IL: NSSE.

Drasgow, F. (2003). Intelligence and the Workplace. In W. C. Borman, D. R. Ilgen, \& R. J. Klimoski (Eds.), Handbook of Psychology (pp. 107-130, Vol. 12). Hoboken, NJ: John Wiley and Sons.

Edmonds, R. R. (1981). Making Public Schools Effective. Social Policy, 12, 56-60.

Flavell, J. H., Botkin, P. J., \& Fry, C. L. (1968). The Development of Role Taking and Communication Skills in Children. New York: Wiley. 
Friedman, I., \& Brama, R. (2010). The Professional Self-Efficacy of the School Principal: The Concept and Its Components. Iyunim Be'minhal Ha'chinuch, 30, 57-94. (In Hebrew)

Gardner, H. (1985). Frames of Mind. New York: Basic Books.

Gardner, J. W. (1990). On Leadership. New York: Free Press.

Glaser, B. G., \& Strauss, A. L. (1967). The Discovery of Grounded Theory. New Brunswick, NJ: Aldin Transactions.

Glatter, R. (1989). Educational Institutions and Their Environments. Managing the Boundaries. Milton Keynes: Open University Press.

Golman, D. (2009). Social Intelligence. Tel-Aviv: Aliyat Hagag, Yediot Aharonot, Hemed. (In Hebrew)

Gross, J. J. (1998). The Emerging Field of Emotion Regulation: An Integrative Review. Review of General Psychology, 5, 25-34. https://doi.org/10.1037/1089-2680.2.3.271

Gross, J. J., \& Thompson, R. A. (2007). Emotion Regulation: Conceptual Foundation. In J. J. Gross (Ed.), Handbook of Emotion Regulation (pp. 3-4). New York: Guilford.

Gross, J. J., Richards, J. M., \& John, O. P. (2006). Emotion Regulation in Everyday Life. In D. K. Snyder, J. A. Simpson, \& J. N. Hughes (Eds.), Emotion Regulation in Couples and Families: Pathways to Dysfunction and Health (pp. 13-35). Washington DC: American Psychological Association. https://doi.org/10.1037/11468-001

Gunter, B. (2019). Personality Traits in Online Communication. New York: Routledge. https://doi.org/10.4324/9780429281563

Guttman, L. (1959). Introduction to Facet Design and Analysis. In Proceedings of the Fifteenth International Congress of Psychology (pp. 130-132). Amsterdam: North Holland. https://doi.org/10.1016/0001-6918(59)90023-X

Handy, C., \& Aitken, R. (1990). Understanding Schools as Organizations. Harmondsworth: Penguin.

Hogg, M. A. (2010). Influence and Leadership. In S. T. Fiske, D. T. Gilbert, \& G. Lindzey (Eds.), Handbook of Social Psychology (5th ed., pp. 1166-1208). Hoboken, NJ: John Wiley and Sons.

Jirasinghe, D., \& Lyons, G. (1996). The Competent Head. London: Falmer.

Judge, T. A., Bono, J. E., Ilies, R., \& Gerhardt, M. W. (2002). Personality and Leadership: A Quantitative and Qualitative Review. Journal of Applied Psychology, 87, 765-780. https://doi.org/10.1037/0021-9010.87.4.765

Katz, R. L. (1955). Skills of an Effective Administrator. Harvard Business Review, 33, 33-42.

Kellerman, B. (2004). Bad Leadership: What It Is, How It Happens, Why It Matters? Cambridge, MA: Harvard Business School Press.

Kotter, J. P. (1990). A Force for Change. New York: Free Press.

Leithwood, K., Harris, A., \& Hopkins, D. (2020). Seven Strong Claims about Successful Leadership Revisited. School Leadership \& Management, 40, 5-22. https://doi.org/10.1080/13632434.2019.1596077

LePine, J. A., Hollenbeck, J. R., Ilgen, D. R., \& Hedlund, J. (1997). Effects of Individual Differences on the Performance of Hierarchical Decision-Making Teams: Much More than “G”. Journal of Applied Psychology, 82, 899-926.

https://doi.org/10.1037/0021-9010.82.5.803

Mann, F. C. (1965). Toward an Understanding of the Leadership Role in Formal Organization. In R. Dubin, G. C. Homans, F. C. Mann, \& D. C. Miller (Eds.), Leadership and 
Productivity (pp. 124-154). San Francisco, CA: Chandler.

Marshal-Mies, J. C., Fleishman, E. A., Martin, J. A., Zaccaro, S. J., Baughman, W. A., \& McGee, M. L. (2000). Development and Evaluation of Cognitive and Metacognitive Measures for Predicting Leadership Potential. Leadership Quarterly, 11, 135-153. https://doi.org/10.1016/S1048-9843(99)00046-6

Maslovaty, N., \& Levy, S. (2001). A Comparative Approach in Developing a Structural Value Theory. In D. Elizur (Ed.), Facet Theory. Integrating Theory Construction with Data Analysis (pp. 21-32). Prague: Facet Theory Association.

Maxwell, A., \& Riley, P. (2016). Emotional Demands, Emotional Labour and Occupational Outcomes in School Principals Modelling the Relationships. Educational Management Administration \& Leadership, 45, 484-502.

https://doi.org/10.1177/1741143215607878

McAdams, D. P., \& Pals, J. L. (2007). The Role of Theory in Personality Research. In R. W. Robins, R. C. Fraley, \& R. F. Krueger (Eds.), Handbook of Research Methods in Personality Psychology (pp. 3-20). New York: The Guilford Press.

McCrae, R. R., \& Costa, P. T. (2008). The Five-Factor Theory of Personality. In O. P. John, R. W. Robins, \& L. A. Pervin (Eds.), Handbook of Personality (pp. 159-181). New York: The Guilford Press.

Michel, G. J. (1995). What Are the Principal's Skills in School Communications? In Meeting of the Management Institute. Management Institute.

Northfields, S. (2014). Multidimensional Trust: How Beginning Principals Build upon Trust with Their Staff. International Journal of Leadership in Education, 17, 410-441. https://doi.org/10.1080/13603124.2013.825011

Northouse, P. (2013). Leadership: Theory and Practice. Thousand Oaks, CA: Sage.

O'Sullivan, M., Guilford, J. P., \& deMill, R. (1965). The Measurement of Social Intelligence (Psychological Laboratory Report No. 34). Los Angeles, CA: University of Southern California.

Organ, D. W., \& Bateman, T. S. (1991). Organizational Behavior. Homewood, IL: Irwin.

Purdie, J. (2014). Key Factors in Early Headship Development in the Scottish Secondary School Sector. An Analytical Autoethnography. Doctoral Dissertation, Glasgow: University of Glasgow.

Reid, K., Hopkins, D., \& Holly, P. (1988). Towards the Effective School. Oxford: Blackwell.

Riggio, R. E. (1986). Assessment of Basic Social Skills. Journal of Personality and Social Psychology, 51, 649-660. https://doi.org/10.1037/0022-3514.51.3.649

Robbins, S. P., \& Judge, T. (2009). Essentials of Organizational Behaviour (13th ed.). Englewood Cliffs, NJ: Prentice Hall.

Rollinson, D. (2002). Organizational Behavior and Analysis (2nd ed.). Harlow: Pearson Education Limited.

Sakis, H., Ekinci, A., \& Saricami, H. (2019). Teachers' Perceptions of Their Managers' Skills and Their Own Self Efficacy Levels. International Journal of Leadership in Education.

Salovey, P., \& Mayer, J. D. (1990). Emotional Intelligence. Imagination, Cognition and Personality, 9, 185-211. https://doi.org/10.2190/DUGG-P24E-52WK-6CDG

Sammons, P. (1999). School Effectiveness. Lisse: Swets and Zeitlinger.

Sebastian, J., Allensworth, E., Wiedermann, W., Hochbein, C., \& Cunningham, M. (2019). Principal Leadership and School Performance: An Examination of Instructional 
Leadership and Organizational Management. Leadership and Policy in Schools, 18, 591-613. https://doi.org/10.1080/15700763.2018.1513151

Shye, S., Elizur, D., \& Hoffman, M. (1994). Introduction to Facet Theory. Thousand Oaks, CA: Sage. https://doi.org/10.4135/9781412984645

Spencer, L. M., \& Spencer, S. M. (1993). Competence at Work. Models for Superior Performance. New York: John Wiley and Sons.

Stogdill, R. (1974). Handbook of Leadership. New York: Free Press.

Taggar, S. R., Hackett, P., \& Saha, S. (1999). Leadership Emergence in Autonomous Work Teams: Antecedents and Outcomes. Personnel Psychology, 52, 899-926. https://doi.org/10.1111/j.1744-6570.1999.tb00184.x

Tamir, M., Mitchell, C., \& Gross, J. J. (2008). Hedonic and Instrumental Motives in Anger Regulation. Psychological Science, 19, 324-328. https://doi.org/10.1111/j.1467-9280.2008.02088.x

VandenBos, G. R. (2006). APA Dictionary of Psychology. Washington DC: American Psychological Association.

Winter, D. G., John, O. P., Stewart, A. J., Klohnen, E. C., \& Duncan, L. E. (1998). Traits and Motives: Towards an Integration of Two Strategies in Personality Research. Psychological Review, 105, 230-250. https://doi.org/10.1037/0033-295X.105.2.230

Yukl, G. (1998). Leadership in Organizations. Upper Saddle, NJ: Prentice Hall. 